\title{
Continuous Set Set Data Type
}

National Cancer Institute

\section{Source}

National Cancer Institute. Continuous Set Set Data Type. NCI Thesaurus. Code C95642.

A data type comprised an enumeration of a set of unordered, quantitative simple values. 